\title{
PARA-ORTHOGONAL RATIONAL MATRIX-VALUED FUNCTIONS ON THE UNIT CIRCLE
}

\author{
BERND FRITZSCHE, BERND KIRSTEIN AND ANDREAS LASAROW
}

\begin{abstract}
In this paper, we continue previous investigations with the ultimate goal being a Szegó theory for orthogonal rational matrix functions. We implement here the concept of paraorthogonal functions on the unit circle in the context of rational matrix functions and present some fundamental properties of the para-orthogonal functions in question. We discuss, among other things, the relationship between these functions and orthogonal rational matrix functions as well as existence criteria and some para-orthogonal functions of particular interest.
\end{abstract}

Mathematics subject classification (2010): Primary 47A56, 42C05; Secondary 30E05.

Keywords and phrases: Para-orthogonal rational matrix functions, orthogonal rational matrix functions, reproducing kernels, nonnegative Hermitian matrix Borel measures on the unit circle.

\section{REFERENCES}

[1] D. Z. ARov, Regular J-inner matrix-functions and related continuation problems, Operator Theory: Adv. and Appl. 43, Birkhäuser, Basel 1990, pp. 63-87.

[2] D. Z. Arov AND H. Dym, J-Contractive Matrix Valued Functions and Related Topics, Encyclopedia of Math. and its Appl. 116, Cambridge University Press, Cambridge 2008.

[3] E. Berriochoa, A. Cachafeiro, And F. Marcellán, A new numerical quadrature formula on the unit circle, Numer. Algorithms 44 (2007), 391-401.

[4] R. BRessan, S. F. Menegasso, AND A. SRI RAngA, Szegó polynomials: quadrature rules on the unit circle and on $[-1,1]$, Rocky Mountain J. Math. 33 (2003), 567-584.

[5] A. BultheEl AND M. J. CANTERO, A matricial computation of rational quadrature formulas on the unit circle, Numer. Algorithms 52 (2009), 47-68.

[6] A. Bultheel, R. Cruz-Barroso, K. Deckers, and P. González-Vera, Rational Szegó quadratures associated with Chebyshev weight functions, Math. Comp. 78 (2009), 1031-1059.

[7] A. Bultheel, P. GonzÁlez-Vera, E. Hendriksen, And O. NJÅstad, a Szegö theory for rational functions, Report TW 131, Department of Computer Science, K.U. Leuven 1990.

[8] A. Bultheel, P. González-Vera, E. Hendriksen, and O. NJÅstad, Orthogonal rational functions and quadrature on the unit circle, Numer. Algorithms 3 (1992), 105-116.

[9] A. BultheEl, P. GonZÁLEZ-VERA, E. HENDRIKSEN, AND O. NJÅSTAD, Quadrature formulas on the unit circle based on rational functions, J. Comput. Appl. Math. 50 (1994), 159-170.

[10] A. Bultheel, P. GonzÁlez-Vera, E. Hendriksen, and O. NJÅstad, Orthogonal Rational Functions, Cambridge Monographs on Applied and Comput. Math. 5, Cambridge University Press, Cambridge 1999.

[11] A. Bultheel, P. González-Vera, E. Hendriksen, And O. NJÅstad, Quadrature and orthogonal rational functions, J. Comput. Appl. Math. 127 (2001), 67-91.

[12] A. Bultheel, P. González-Vera, E. Hendriksen, And O. Njåstad, Rational quadrature formulas on the unit circle with prescribed nodes and maximal domain of validity, IMA J. Numer. Anal. 30 (2010), 940-963.

[13] A. Bultheel, P. González-Vera, E. Hendriksen, and O. NJÅstad, Computation of rational Szegó-Lobatto quadrature formulas, Appl. Numer. Math. 60 (2010), 1251-1263.

[14] A. BultheEL AND A. LASAROW, On the existence of para-orthogonal rational functions on the unit circle, Analysis (Munich) 30 (2010), 301-316. 
[15] M. J. CANTERo, R. CruZ-Barroso, And P. GonZÁlez-Vera, A matrix approach to the computation of quadrature formulas on the unit circle, Appl. Numer. Math. 58 (2008), 296-318.

[16] M. J. CANTERo, L. Moral, AND L. VelázQueZ, Measures and para-orthogonal polynomials on the unit circle, East J. Approx. 8 (2002), 447-464.

[17] A. E. Choque Rivero, A. Lasarow, And A. Rahn, On ranges and Moore-Penrose inverses related to matrix Carathéodory and Schur functions, Complex Anal. Oper. Theory 5 (2011), 513-543.

[18] R. CruZ-Barroso, L. Daruis, P. GonZÁlez-Vera, ANd O. NJÅstad, Sequences of orthogonal Laurent polynomials, bi-orthogonality and quadrature formulas on the unit circle, J. Comput. Appl. Math. 206 (2007), 950-966.

[19] R. CRUZ-BARRoso ANd P. GonZÁLEZ-VERA, On reproducing kernels and para-orthogonal polynomials on the unit circle, Rev. Acad. Canaria Cienc. 15 (2003), 79-91.

[20] D. DAmANIK, A. PUSHNitsKi, AND B. SimOn, The analytic theory of matrix orthogonal polynomials, Surv. Approx. Theory 4 (2008), 1-85.

[21] L. DARUis, P. GonZÁleZ-Vera, AND F. MARCEllán, Gaussian quadrature formulae on the unit circle, J. Comput. Appl. Math. 140 (2002), 159-183.

[22] L. DARUIS, O. NJÅSTAD, AND W. VAN ASSCHE, Para-orthogonal polynomials in frequency analysis, Rocky Mountain J. Math. 33 (2003), 629-645.

[23] K. Deckers, A. Bultheel, R. Cruz-Barroso, and F. Perdomo-Pío, Positive rational interpolatory quadrature formulas on the unit circle and the interval, Appl. Numer. Math. 60 (2010), $1286-1299$.

[24] B. DE LA CALLE YSERN, Error bounds for rational quadrature formulae of analytic functions, Numer. Math. 101 (2005), 251-271.

[25] B. DE LA CALLE YSERn AND P. GONZÁLEZ-VERA, Rational quadrature formulae on the unit circle with arbitrary poles, Numer. Math. 107 (2007), 559-587.

[26] M. M. DJRBASHIAN, Orthogonal systems of rational functions on the circle with given set of poles, (Russian) Dokl. Akad. Nauk SSSR 147 (1962), 1278-1281.

[27] V. K. Dubovoj, B. Fritzsche, And B. Kirstein, Matricial Version of the Classical Schur Problem, Teubner-Texte zur Math. 129, Teubner, Leipzig 1992.

[28] B. FRITZSCHE, B. KIRSTEIN, AND A. LASAROW, On a moment problem for rational matrix-valued functions, Linear Algebra Appl. 372 (2003), 1-31.

[29] B. FRITZSCHE, B. KirSTEIN, AND A. LASAROw, On rank invariance of moment matrices of nonnegative Hermitian-valued Borel measures on the unit circle, Math. Nachr. 263/264 (2004), 103-132.

[30] B. Fritzsche, B. Kirstein, AND A. LASAROw, Orthogonal rational matrix-valued functions on the unit circle, Math. Nachr. 278 (2005), 525-555.

[31] B. Fritzsche, B. Kirstein, AND A. LASARow, Orthogonal rational matrix-valued functions on the unit circle: Recurrence relations and a Favard-type theorem, Math. Nachr. 279 (2006), 513-542.

[32] B. Fritzsche, B. KiRSTEIn, AND A. LASAROw, On a class of extremal solutions of the nondegenerate matricial Carathéodory problem, Analysis (Munich) 27 (2007), 109-164.

[33] B. Fritzsche, B. Kirstein, AND A. LASAROw, On a class of extremal solutions of a moment problem for rational matrix-valued functions in the nondegenerate case I, Math. Nachr. 283 (2010), $1706-1735$.

[34] B. Fritzsche, B. Kirstein, And A. LASARow, On a class of extremal solutions of a moment problem for rational matrix-valued functions in the nondegenerate case II, J. Comput. Appl. Math. 235 (2010), 1008-1041.

[35] W. GAUTSCHI, A survey of Gauss-Christoffel quadrature formulae, E.B. Christoffel, The Influence of His Work on Mathematical and Physical Sciences, Birkhäuser, Basel 1981, pp. 72-147.

[36] W. GAUTSCHI, L. GoRI, AND M. L. Lo CASCiO, Quadrature rules for rational functions, Numer. Math. 86 (2000), 617-633.

[37] JA. L. Geronimus, Polynomials orthogonal on a circle and their applications, (Russian) Zapiski Naučno-Issled. Inst. Mat. Meh. Har'kov. Mat. Obšč. 19 (1948), 35-120.

[38] U. Grenander and G. Szegő, Toeplitz Forms and Their Applications, California Monographs in Math. Sci., University of California Press, Berkeley 1958.

[39] L. B. GoLINSKII, Quadrature formula and zeros of para-orthogonal polynomials on the unit circle, Acta Math. Hungar. 96 (2002), 169-186.

[40] W. B. Jones, O. NJÅSTAD, AND W. J. Thron, Moment theory, orthogonal polynomials, quadrature, and continued fractions associated with the unit circle, Bull. London Math. Soc. 21 (1989), 113-152. 
[41] S. V. KHRUSHCHEV, Schur's algorithm, orthogonal polynomials, and convergence of Wall's continued fractions in $L^{2}(\mathbb{T})$, J. Approx. Theory 108 (2001), 161-248.

[42] R. L. LAmblém, J. H. MCCABE, M. A. PiñAR, AND A. SRi RAnGA, Szegó type polynomials and para-orthogonal polynomials, J. Math. Anal. Appl. 370 (2010), 30-41.

[43] A. LASAROW, More on a class of extremal solutions of a moment problem for rational matrix-valued functions in the nondegenerate case, J. Approx. Theory 163 (2011), 864-887.

[44] O. NJÅSTAD AND L. VELÁZQUEZ, Wall rational functions and Khrushchev's formula for orthogonal rational functions, Constr. Approx. 30 (2009), 277-297.

[45] M. Rosenberg, The square integrability of matrix-valued functions with respect to a non-negative Hermitian measure, Duke Math. J. 31 (1964), 291-298.

[46] J. C. SAntos-LEón, Computation of integrals over the unit circle with nearby poles, Appl. Numer. Math. 36 (2001), 179-195.

[47] B. Simon, Orthogonal Polynomials on the Unit Circle, Part 1: Classical Theory, Amer. Math. Soc. Coll. Pub. 54, Providence, R. I. 2005.

[48] B. Simon, Rank one perturbations and the zeros of paraorthogonal polynomials on the unit circle, J. Math. Anal. Appl. 329 (2007), 376-382.

[49] B. Simon, Weak convergence of CD kernels and applications, Duke Math. J. 146 (2009), 305-330.

[50] A. SinAP, Gaussian quadrature for matrix valued functions on the unit circle, Electron. Trans. Numer. Anal. 3 (1995), 96-115.

[51] A. SinAP And W. VAn Assche, Orthogonal matrix polynomials and applications, J. Comput. Appl. Math. 66 (1996), 27-52.

[52] M. STOICIU, The statistical distribution of the zeros of random paraorthogonal polynomials on the unit circle, J. Approx. Theory 139 (2006), 29-64.

[53] G. Szegô, Orthogonal Polynomials, Amer. Math. Soc. Coll. Publ. 23, Providence, R. I. 1939.

[54] W. VAN Assche, Orthogonal polynomials in the complex plane and on the real line, Fields Inst. Commun. 14, Amer. Math. Soc., Providence, R. I. 1997, pp. 211-245.

[55] L. VELÁZQUEZ, Spectral methods for orthogonal rational functions, J. Funct. Anal. 254 (2008), 954986.

[56] M. L. Wong, First and second kind paraorthogonal polynomials and their zeros, J. Approx. Theory 146 (2007), 282-293. 